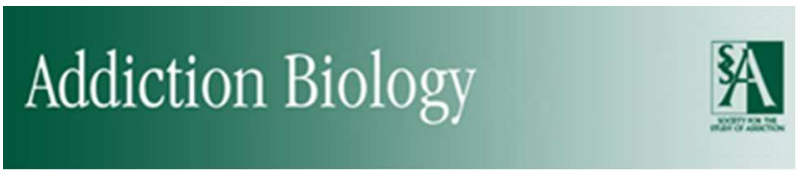

\title{
Frustrated expected reward induces differential transcriptional changes in the mouse brain
}

\begin{tabular}{|c|c|}
\hline Journal: & Addiction Biology \\
\hline Manuscript ID: & $A B-05-2014-0139 . R 1$ \\
\hline Wiley - Manuscript type: & Original Article \\
\hline Date Submitted by the Author: & $\mathrm{n} / \mathrm{a}$ \\
\hline Complete List of Authors: & $\begin{array}{l}\text { Martin-Garcia, Elena; Universitat Pompeu Fabra (UPF), PRBB, Laboratori de } \\
\text { Neurofarmacologia, Departament de Ciències Experimentals i de la Salut } \\
\text { Fernàndez-Castillo, Noelia; Universitat de Barcelona, Departament de } \\
\text { Genètica; Instituto de Salud Carlos III, Centro de Investigación Biomédica } \\
\text { en Red de Enfermedades Raras (CIBERER); Universitat de Barcelona, } \\
\text { Institut de Biomedicina de la Universitat de Barcelona (IBUB) } \\
\text { Burokas, Aurelijus; Universitat Pompeu Fabra (UPF), PRBB, Laboratori de } \\
\text { Neurofarmacologia, Departament de Ciències Experimentals i de la Salut } \\
\text { Gutiérrez-Cuesta, Javier; Universitat Pompeu Fabra (UPF), PRBB, } \\
\text { Laboratori de Neurofarmacologia, Departament de Ciències Experimentals i } \\
\text { de la Salut } \\
\text { Sanchez-Mora, Cristina; Hospital Universitari Vall d'Hebron, Department of } \\
\text { Psychiatry; Biomedical Network Research Center on Mental Health } \\
\text { (CIBERSAM). Instituto de Salud Carlos III, ; Hospital Universitari Vall } \\
\text { d'Hebron, Psychiatric Genetics Unit } \\
\text { Casas, Miquel; Hospital Universitari Vall d'Hebron, Department of } \\
\text { Psychiatry; Biomedical Network Research Center on Mental Health } \\
\text { (CIBERSAM). Instituto de Salud Carlos III, ; Universitat Autònoma de } \\
\text { Barcelona, Department of Psychiatry and Legal Medicine } \\
\text { Ribasés, Marta; Hospital Universitari Vall d'Hebron, Department of } \\
\text { Psychiatry; Biomedical Network Research Center on Mental Health } \\
\text { (CIBERSAM). Instituto de Salud Carlos III, ; Hospital Universitari Vall } \\
\text { d'Hebron, Psychiatric Genetics Unit } \\
\text { Cormand, Bru; Universitat de Barcelona, Departament de Genètica; } \\
\text { Instituto de Salud Carlos III, Centro de Investigación Biomédica en Red de } \\
\text { Enfermedades Raras (CIBERER); Universitat de Barcelona, Institut de } \\
\text { Biomedicina de la Universitat de Barcelona (IBUB) } \\
\text { Maldonado, Rafael; Universitat Pompeu Fabra (UPF), PRBB, Laboratori de } \\
\text { Neurofarmacologia, Departament de Ciències Experimentals i de la Salut }\end{array}$ \\
\hline Keywords: & palatable food, frustration, gene expression \\
\hline Abstract: & $\begin{array}{l}\text { Frustration represents a particular aspect of the addictive process that is } \\
\text { related to loss of control when the expected reward is not obtained. We } \\
\text { aim to study the consequences of frustrated expected reward on gene } \\
\text { expression in the mouse brain. For this purpose, we used an operant model } \\
\text { of frustration using palatable food as reward combined with microarrays. } \\
\text { Transcriptomic profiles of frontal cortex, ventral striatum and hippocampus }\end{array}$ \\
\hline
\end{tabular}


Page 1 of 43

Addiction Biology

were analysed in five groups of mice: (1) positive control receiving palatable food and the cue light as conditioned stimulus; (2) frustrated group only receiving the cue light; (3) extinction learning group that did not receive palatable food nor the light; (4) negative control that never received the reinforcer nor the light during the whole experiment, and (5) yoked that received palatable food passively. Gene expression changes produced by frustration were revealed in the frontal cortex and ventral striatum, but not in the hippocampus. Most of the changes, such as the modification of the dopamine-DARPP-32 signalling pathway, were common in both areas and estimated to have neuronal origin. Extinction learning induced transcriptional changes only in the ventral stratum, with most genes showing down-regulation and without alteration in the dopamineDARPP-32 signalling pathway. Active palatable food seeking behaviour induced changes in gene expression in ventral striatum mainly affecting cell communication. In conclusion, frustration behaviour induced changes in frontal cortex and ventral stratum mainly related to dopamine-DARPP32 signalling that could play an important role in the loss of behavioural control during the addictive processes.

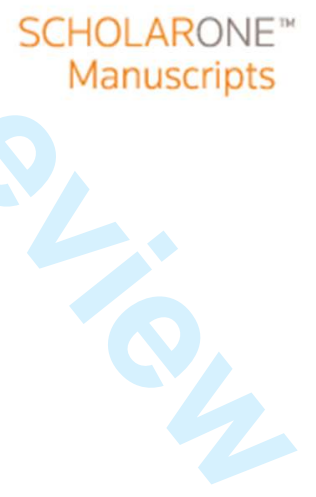




\section{FRUSTRATED EXPECTED REWARD INDUCES DIFFERENTIAL TRANSCRIPTIONAL CHANGES IN THE MOUSE BRAIN}

Elena Martín-García ${ }^{\mathrm{a}^{*}}$, Noelia Fernández-Castillo ${ }^{\mathrm{b}, \mathrm{c}, \mathrm{d}^{*}}$, Aurelijus Burokas ${ }^{\mathrm{a}^{*}}$, Javier Gutiérrez-Cuesta $^{\mathrm{a}}$, Cristina Sánchez-Mora ${ }^{\mathrm{f}, \mathrm{g}, \mathrm{h}}$, Miguel Casas ${ }^{\mathrm{f}, \mathrm{gj}}$, Marta Ribasés ${ }^{\mathrm{f}, \mathrm{g}, \mathrm{h}}$, Bru Cormand $^{\mathrm{b}, \mathrm{c}, \mathrm{d}+}$ and Rafael Maldonado ${ }^{\mathrm{a}+* * *}$

${ }^{a}$ Laboratori de Neurofarmacologia Departament de Ciències Experimentals $i$ de la Salut, Universitat Pompeu Fabra, PRBB, C/ Dr. Aiguader 88, 08003, Barcelona, Spain,

${ }^{\mathrm{b}}$ Departament de Genètica, Facultat de Biologia, Universitat de Barcelona, Barcelona, Spain,

c Centro de Investigación Biomédica en Red de Enfermedades Raras (CIBERER, Instituto de Salud Carlos III, Spain,

${ }^{\mathrm{d}}$ Institut de Biomedicina de la Universitat de Barcelona (IBUB), Barcelona, Spain,

${ }^{\mathrm{f}}$ Department of Psychiatry, Hospital Universitari Vall d'Hebron, Barcelona, Spain,

${ }^{\mathrm{g}}$ Biomedical Network Research Center on Mental Health (CIBERSAM), Instituto de Salud Carlos III, Spain,

${ }^{\mathrm{h}}$ Psychiatric Genetics Unit, Hospital Universitari Vall d'Hebron, Barcelona, Spain.

${ }^{\mathbf{j}}$ Department of Psychiatry and Legal Medicine, Universitat Autònoma de Barcelona, Catalonia, Spain

* These authors have equally contributed to this work

${ }^{+}$These authors have equally supervised this work

***To whom correspondence should be addressed. E-mail: rafael.maldonado@upf.edu

Category of the article: Regular research article

Number of references: 43

Words in Abstract: 248

Words in Article (excluding abstract, references and figure legends): 5240

Number of figures: 7

Number of tables: 3

Supporting information: Yes

Short title: Microarrays and frustration 
E. Martín-García

\begin{abstract}
Frustration represents a particular aspect of the addictive process that is related to loss of control when the expected reward is not obtained. We aim to study the consequences of frustrated expected reward on gene expression in the mouse brain. For this purpose, we used an operant model of frustration using palatable food as reward combined with microarrays. Transcriptomic profiles of frontal cortex, ventral striatum and hippocampus were analysed in five groups of mice: (1) positive control receiving palatable food and the cue light as conditioned stimulus; (2) frustrated group only receiving the cue light; (3) extinction learning group that did not receive palatable food nor the light; (4) negative control that never received the reinforcer nor the light during the whole experiment, and (5) yoked that received palatable food passively. Gene expression changes produced by frustration were revealed in the frontal cortex and ventral striatum, but not in the hippocampus. Most of the changes, such as the modification of the dopamine-DARPP-32 signalling pathway, were common in both areas and estimated to have neuronal origin. Extinction learning induced transcriptional changes only in the ventral striatum, with most genes showing down-regulation and without alteration in the dopamine-DARPP-32 signalling pathway. Active palatable food seeking behaviour induced changes in gene expression in ventral striatum mainly affecting cell communication. In conclusion, frustration behaviour induced changes in frontal cortex and ventral striatum mainly related to dopamine-DARPP-32 signalling that could play an important role in the loss of behavioural control during the addictive processes.
\end{abstract}

Key Words: Palatable food, frustration, gene expression, operant behaviour, progressive ratio, transcriptomics, DARPP-32. 
E. Martín-García

\section{Introduction}

A particular behavioural aspect that has received less attention in the study of addictive processes and eating disorders is the consequence of the frustrated state occurring when the reward is not available. The omission of reward after repeated exposure to consistent reinforcement generates a state of frustration (Amsel, 1958) that can be measured using a novel instrumental behavioural paradigm recently developed in mice (Burokas et al., 2012). In this model, the most efficient rewarding stimulus omitted after repeated training in an operant paradigm was palatable food, and the frustrated expectation of reward produced perseverative operant responding and aggressiveness (Burokas et al., 2012). In agreement, human subjects prevented from reaching expected rewards show affective alterations that include aggressiveness, irritability and anxiety (Henna et al., 2008). This negative emotional state specifically generated by frustration could represent an early symptom of the later development of the compulsive behaviour characteristic of the behavioural loss of control occurring in addictive-like processes. Drug addiction and eating disorders share common mechanisms that reflect imbalances in the responses of the brain to rewarding stimuli. Thus, eating disorders leading to obesity are characterized by compulsive food consumption and inability to stop from eating despite the negative consequences. These symptoms are remarkably parallel to those of drug addiction, and the present model is therefore relevant to evaluate these manifestations of addictive-like behaviour promoted by palatable food. Other authors have developed animal models of compulsive overeating associated with some forms of frustration that appeared after cue presentation and food omission. These models of binge eating are based on an interaction between cyclic food restriction and environmental stress. In these models, pre-exposure to environmental cues that predict food availability increases operant responding for food, which correlates with increased 
hypothalamic-pituitary-adrenal axis activation (Cifani et al., 2009a; Cifani et al., 2009b).

Genetic studies have been used to determine the degree to which individual behavioural differences are due to genetic variations or to environmental influences that coordinate the brain circuits, and to identify the specific genes that contribute to individual behavioural differences (Hamer, 2002). One of the most used approaches involve the evaluation of gene expression changes at transcriptomic level in animal models. Using expression microarrays technology, it has recently been possible to identify alterations in the expression of numerous genes involved in the modulation of key signalling pathways that drive complex behaviours, such as drug self-administration in mice (Fernandez-Castillo et al., 2012). Similarly, previous studies have identified changes in gene expression related to dopaminergic and/or adrenergic systems in specific limbic structures due to caloric restriction and obesity in mice (Mathes et al., 2010; Lee et al., 2010). In the same line, obesity prone rats have decreased dopamine receptor expression and extracellular dopamine levels in limbic structures (Geiger et al., 2008;

Geiger et al., 2009), and dopamine D1 receptors have been associated with palatable food intake (Terry and Katz, 1992; Katz et al., 2006).

The aim of the present work was to study the differential transcriptional changes induced by frustrated expected reward of palatable food in the mouse brain, specifically in the frontal cortex, ventral striatum and hippocampus. The frontal cortex plays a complex role in cognition, including inhibitory control, decision making and emotional regulation, and dysfunctions in this region might impair the control over compulsive food and drug intake (Volkow and Fowler, 2000; Kalivas, 2004; Tomasi and Volkow, 2013). Ventral striatum is involved in driving the initial motivation for the different rewarding stimuli and plays a crucial role in habits formation (Everitt et al., 2008). The 
E. Martín-García

hippocampus is essential for memory and conditioning to reward associated cues that promote reward seeking behaviour and it plays a crucial role in relapse to drug and food consumption (Haber et al., 2006). These brain regions have been closely related to addictive processes and overeating and represent excellent targets to evaluate the transcriptomic consequences of frustration to an expected reward. 
E. Martín-García

\section{Materials and methods}

\section{Animals}

Male C57BL/6J mice (Charles River, France), weighing 24-26 g at the beginning of the experiment were used in this study. Mice were housed individually in controlled laboratory conditions with the temperature maintained at $21 \pm 1^{\circ} \mathrm{C}$ and humidity at $55 \pm$ $10 \%$. Mice were tested during the first hours of the dark phase of a reversed light/dark cycle (lights off at $8.00 \mathrm{~h}$ and on at $20.00 \mathrm{~h}$ ). Mice were food-deprived ( $85 \%$ of the initial weight) and water was available ad libitum. Animal procedures were conducted in strict accordance with the guidelines of the European Communities Directive 86/609/EEC regulating animal research and were approved by the local ethical committee (CEEA-PRBB).

\section{Food operant seeking behaviour apparatus}

Operant responding maintained by food was performed in mouse operant chambers (Model ENV-307A-CT, Med Associates, Georgia, VT, USA) equipped with two retractable levers, one randomly selected as active lever and the other as inactive. Pressing on the active lever resulted in a pellet delivery together with a stimulus-light named conditioned stimulus (CS), located above the active lever, while pressing on the inactive lever had no consequences. The chambers were made of aluminium and acrylic, and were housed in sound- and light-attenuated boxes equipped with fans to provide ventilation and white noise. A food dispenser equidistant between the two levers permitted delivery of food pellets when required.

\section{Highly palatable food pellets}


E. Martín-García

During the operant self-administration sessions, animals were exposed to $20 \mathrm{mg}$ highly palatable food pellets (TestDiet, Richmond, IN, USA) with a formula that has similar caloric value of standard food $(20.5 \%$ protein, $12.7 \%$ fat and $66.8 \%$ carbohydrate, with a caloric value of $3.48 \mathrm{kcal} / \mathrm{g}$ ). These pellets were modified by the addition of chocolate flavor ( $2 \%$ pure unsweetened cocoa) and with the addition of sucrose that represented the $50.1 \%$ of the carbohydrate content. Pellets were presented only during the operant behavioral sessions. Otherwise, animals were maintained on standard chow for their daily food intake.

\section{Experimental design}

C57BL/6J male mice $(\mathrm{n}=45)$ were trained during $1 \mathrm{~h}$ for 10 consecutive days to leverpress for chocolate-flavoured food-pellets as reward, paired with the presentation of a cue-light serving as CS, on a fixed ratio (FR) 1 schedule of reinforcement followed by 10 sessions under FR5 and 10 sessions under FR10. The criteria for acquisition of operant responding were achieved when mice maintained a stable responding with less than $20 \%$ deviation from the mean of the total number of food-pellets earned in three consecutive sessions, with at least $75 \%$ responding on the reinforced lever, and a minimum of 10 reinforcements per session (Burokas et al., 2012). Mice were fooddeprived during the whole experiment at $85 \%$ of their ad libitum initial weight adjusted for growth. Food deprivation was applied to facilitate operant learning and to optimize the number of responses in each session. After the 30 FR sessions, animals were trained during 10 days in a progressive ratio $(\mathrm{PR})$ schedule where the response requirement to earn the reinforcer escalated according to the following series: 1-2-3-5-12-18-27-40-6085-115-150-300. The maximum duration of the PR session was $2 \mathrm{~h}$ or until mice did not respond on any lever within $1 \mathrm{~h}$. After 10 days of PR with an end-point ratio of 300, one additional session of PR was performed under similar conditions with an end-point of 
150. Mice that reached this end-point were divided in 5 different experimental conditions as previously reported (Burokas et al., 2012): 1) a first group receiving chocolate-flavoured pellets and the cue-light, interpreted as the positive control, 2) a second group that only received the cue-light, interpreted as the frustrating event group, 3) a third group that did not receive chocolate nor the cue-light, interpreted as the extinction learning situation, 4) An additional control group that did not receive the reinforcer nor the light during all the phases of the operant training was also included, 5) a group of mice was yoked to the first positive control group during the whole acquisition training period. This last group of mice received chocolate pellets noncontingently, without receiving the $\mathrm{CS}$ at the same time that each master mouse obtained a contingent chocolate administration (Fig. 1). The end-point selected for the last PR session was lower than the breaking point obtained in previous studies under similar experimental conditions $(366.88 \pm 77.73)$ to allow that all mice reach this 150 end-point. After reaching the 150 end-point, animals remained in the training box during 10 additional min without any scheduled consequence when responding in the active lever, and their active and inactive responses were recorded.

Mice were sacrificed by cervical dislocation 20 min after the end of last PR session. The brains were quickly removed and the frontal cortex, ventral striatum and hippocampus were dissected according to the mouse brain atlas (Paxinos and Franklin, 1997). Brain tissues were then frozen by immersion in 2-methylbutane surrounded by dry ice, and stored at $-80^{\circ} \mathrm{C}$ for later quantification of gene expression.

\section{RNA isolation and microarray hybridization}

Forty-five mice (nine animals per group of frustrated, extinction learning, positive control, yoked and negative control) and three brain areas (frontal cortex, ventral 
E. Martín-García

striatum and hippocampus) were used in the expression microarray study. Three pools consisting of three mice per pool were used for each experimental group. The pools were homogeneous in the behavioural results obtained during the 10 additional min after achieving the 150 end-point in the last PR session (number and rate of responses). The pooled individuals were the same for all the brain regions. We used the GeneChip ${ }^{\circledR}$ Mouse Expression Set 430 array (Affymetrix, Santa Clara, CA, USA) that allows inspection of the expression levels of over 39,000 transcripts. A total of 45 chips were used: three pools of three individuals per condition (frustration, extinction learning, positive control, yoked and negative control) and three brain areas (frontal cortex, ventral striatum and hippocampus). See supporting information for additional details of the method.

\section{Quantitative reverse transcription polymerase chain reaction (qRT-PCR)}

To confirm expression changes obtained in the microarray data, we selected genes according to their function for qRT-PCR validation. Total RNA were reversetranscribed using the High Capacity cDNA Reverse Transcription Kit (Applied Biosystems, Foster city, CA, USA). Quantitative Real Time-PCR experiments were performed for 11 genes using the LightCycler 480 II system and the Universal Probe Library (Roche Applied Science, Penzberg, Germany). Gene assays were designed using the Universal ProbeLibrary Assay Design Center software (Roche Applied Science, www.roche-applied-science.com). Sequence of the primers and probes used are available upon request. The genes selected as endogenous controls, Gapdh (glyceraldehyde-3-phosphate dehydrogenase) and Hprt1 (hypoxanthine phosphoribosyltransferase 1), were chosen according to the microarray data. After 
confirming stability across experiments by qRT-PCR, they were used to normalize the relative amounts of mRNA.

\section{Statistical and bioinformatic analyses}

The self-administration behavioural data were analysed using three-way or two-way repeated measures analyses of variance (ANOVA), for the acquisition of operant responding or the operant responding after the last PR150 respectively, with group as between-subject factor and lever (active/inactive) and day or min as within-subjects factors followed by post hoc tests (Newman-Keuls) for individual comparisons when appropriate. Statistical significance was set at $p<0.05$. All results are expressed as mean \pm S.E.M. The statistical analysis was performed using the Statistical Package for Social Science SPSS ${ }^{\circledR} 15.0$ (SPSS Inc, Chicago, USA).

For the microarray data, we used Bioconductor software for $\mathrm{R}$ environment, as described previously (Fernandez-Castillo et al., 2012) (see supporting information for details). We compared the expression patterns of frustrated - positive control, extinction learning- positive control, frustrated - positive control, positive control - yoked, positive control - negative control, and yoked - negative control.

Canonical pathway enrichment analyses were performed using Ingenuity Pathway Analysis 8.8 software (Ingenuity Systems, Redwood city, CA, USA). Kyoto encyclopaedia of genes and genomes (KEGG) pathways as well as Gene Ontology (GO) enrichment analyses were performed using the WebGESTALT software (bioinfo.vanderbilt.edu/webgestalt). The identification of over-represented transcription factor binding sites (TFBSs) was performed using Single Site Analysis with the oPOSSUM 2.0 software (www.cisreg.ca/cgi-bin/oPOSSUM/opossum) (Ho Sui et al., 2005), using the default parameters of the vertebrate Jaspar Core profile, and sorting the 
E. Martín-García

top 20 results by $\mathrm{Z}$-score. Analysis based on the estimation of glial or neuronal origin of transcripts was performed as described before (Sibille et al., 2008). Analyses were only performed in frontal cortex genes and the subset of 47 genes common between frontal cortex and ventral striatum (ventral striatum genes could not be tested since data was not available for this brain area).

In the qRT-PCR experiments, changes in gene expression for each comparison were evaluated using a U-Mann-Whitney nonparametric test, since normality was rejected, and statistical significance was set at $p<0.05$. 


\section{Results}

Frustrated expected reward after operant training to obtain chocolate-flavoured pellets

Acquisition of operant responding maintained by palatable food

The acquisition criteria for operant responding maintained by chocolate-flavoured pellets on FR1 were achieved by all the mice equally. No differences in the acquisition or the maintenance of operant responding under FR1, FR5 or FR10 schedule were revealed among the three experimental groups (frustration, positive control and extinction learning) that acquired operant responding before the PR training (for threeway ANOVA see supporting information, Table S1). During de 10 days of PR training, no differences between the three groups were revealed. None of the animals included in the negative control or yoked groups achieved the acquisition criteria during FR1, FR5, FR10 and PR training, and significant differences were revealed between these two control groups and the other experimental groups from the first day of training (Fig. 2A).

Operant responding after the last PR150

In the last session of $\mathrm{PR}$, the operant responding in the active lever was evaluated during 10 additional min after achieving the end-point 150 , without any scheduled consequence. As expected, none of the animals in the negative control or yoked groups achieved this end-point. As previously reported (Burokas et al., 2012), post-hoc Newman-Keuls comparison revealed that the group that underwent the frustrated delivery of the reward, showed a significant increase in operant responding after this end-point in comparison with the positive control group $(p<0.05$, Fig. 2B). Similar results were obtained in the operant responding rates (lever-presses/min) of the 
E. Martín-García

frustrated group that were significantly higher 2, 5 and 10 min after the end-point compared with the positive control group $(p<0.05)$, (for two-way ANOVA see supporting information, Table S2). Response patterns performed on the active and inactive levers during the 10 additional min after the end-point for representative mice in each experimental group are depicted in Fig. 2 C.

\section{Transcriptional changes induced by frustration or extinction learning}

Transcriptomic profiles of frustrated, extinction and positive control mice were compared in three different brain areas (frontal cortex, ventral striatum and hippocampus), to assess changes in gene expression induced by acute frustration or extinction learning. Significant differences were observed in frontal cortex and ventral striatum in at least one comparison, but no differences in gene expression were observed for any comparison in the hippocampus.

\section{Frustration-induced changes in gene expression}

Under our experimental conditions, the frustration situation induced differences in gene expression in both frontal cortex and ventral striatum. In frontal cortex, 116 genes were differentially expressed only between frustrated and positive control mice, from which almost all of them showed up-regulation in the frustrated mice. No genes showed differential expression between frustrated and extinction learning animals (Fig. 3A, 3B and supporting information, Table S3). In ventral striatum a total of 1,195 genes were differentially expressed only between frustrated and extinction learning mice (Fig. 3A, 3B, and supporting information, Table S4), most of them also up-regulated in the frustrated mice, although no changes could be identified when comparing frustrated and positive control mice. Surprisingly, the expression of 47 of these genes was similarly 
E. Martín-García

changed in both brain areas, i.e., all of them were over-expressed in the frustrated mice (Fig. 3B). In order to identify possible common mechanisms involved in this upregulation, we performed an analysis of over-representation of transcription factor binding sites in up-regulated genes from each brain area as well as in the 47 genes identified in both of them. Binding sites for four transcription factors were overrepresented in the subset of genes identified in each brain region and in the subset of common genes: Nkx2-5, Pdx1, Sox5 and Sry (Table 1). Analysis of canonical pathways enrichment showed that the pathway "CREB signalling in neurons" was enriched in genes differentially expressed in frontal cortex, and "Synaptic long term potentiation", "Glutamate receptor signalling" and "Glutamate degradation" were enriched in ventral striatum (Fig. 3B). Interestingly, the "Dopamine-DARPP-32 feedback in cAMP signalling" was found to be enriched both in frontal cortex and in ventral striatum genes, in which several genes of this pathway were down-regulated or up-regulated (Fig. 3B and 4).

To elucidate common mechanisms between both structures in frustrated mice, we also performed an analysis based on the estimation of glial or neuronal origin of differentially expressed transcripts. Gene transcript origin can be estimated by the ratio of expression between white matter (WM) and grey matter (GM) obtained by array data from adjacent WM samples, as previously described (Sibille et al., 2008). Thus, transcripts are estimated to be enriched in glia if $\mathrm{WM} / \mathrm{GM}>1.5$, in neurons if $\mathrm{WM} / \mathrm{GM}<-1.5$, or both cellular populations if $-1.5<\mathrm{WM} / \mathrm{GM}<1.5$. Using this analysis, we observed a predominance of neuronal genes, especially when considering those genes with a more pronounced over-expression, as visually represented by the overall blue colour in both panels (Fig. 5). 
E. Martín-García

We selected 10 genes among those differentially expressed for validation by qRT-PCR, five in frontal cortex and five in ventral striatum, all of them involved in neurological processes: Crebbp, Cnr1, Plcb1, Nrxn1, Jak1 in frontal cortex and Camk4, Kalrn, Rph3a, Prkcb and Gprin3 in ventral striatum. Up-regulation in frustrated mice of all these genes was confirmed by qRT-PCR, except for Rph3a (Table 2).

\section{Extinction learning induced changes in gene expression}

Only in ventral striatum significant differences in gene expression in the extinction learning mice were revealed: extinction learning vs positive control (235 genes) and extinction learning vs frustrated (1,423 genes) (Fig. 3A). We focused on genes that were differentially expressed in both comparisons in the same direction, a total of 228 transcripts (almost all the genes that showed a differential expression in the extinction learning vs positive control comparison), most of them down-regulated in the extinction learning mice (Fig. 3A, 3C, and supporting information, Table S5). The pathways "ERK5", "Janus kinase (JAK)" and "ciliary neurotrophic factor (CNTF) signalling" were found to be enriched. The pathways "spliceosome" and "RNA degradation" were also enriched in the KEGG pathway analysis, and canonical pathways showed a remarkable involvement of inositol metabolism, synthesis and degradation (Fig. 3C).

We selected six genes among those differentially expressed in the two comparisons for validation by qRT-PCR, all of them involved in neurological processes: Crebbp, Cnrl, Plcb1, Nrxn1, Jak1 and Grit. Down-regulation in extinction learning mice of all these genes was confirmed by qRT-PCR results (Table 3).

\section{Transcriptional changes induced by palatable food self-administration}


E. Martín-García

Gene expression profiles from positive control, yoked and negative control mice were compared in the three brain regions studied to identify transcriptional changes caused by active or passive palatable food administration. Significant differences were observed between the positive control and the yoked mice (624) and also between the positive control and the negative control mice (429), only in ventral striatum (Fig. 6A). No changes in gene expression were observed between the yoked and the negative control mice suggesting that differences exclusively due to palatable food intake could not be identified (Fig. 6A). We focused on genes that were differentially expressed as a consequence of active operant responding to obtain palatable food. For this purpose, we considered only those genes displaying changes in the same direction in the two comparisons: positive control vs yoked and positive control vs negative control (Fig. $6 \mathrm{~B}$ ), and a total of 210 transcripts were differentially expressed due to active operant responding (see supporting information, Table S6). Interestingly, 50 of them corresponding to 48 different genes were involved in cell communication in the GO enrichment analysis (Fig. 6C). The pathways "Neurotrophin signaling pathway" and "MAPK signalling pathways" were also found to be enriched. The analysis of canonical pathways also revealed enrichment of the "cilliary neurotrophic factor (CNTF) signalling". 
E. Martín-García

\section{Discussion}

In the present study we have investigated the consequences of frustrated expected reward on gene expression in the mouse brain using an operant model of palatable food seeking. This model allows to investigate the consequences of the frustrated elimination of reward that produces perseverative operant responding, as previously reported (Burokas et al., 2012). The frustration was specifically driven by the cue light used as CS associated with the reward, and the perseveration in operant responding has been related to compulsive behaviour and loss of control that are core manifestations of human addictive processes (Burokas et al., 2012). Our results reveal that (1) frustration of expected reward changes gene expression in frontal cortex and ventral striatum, in which the dopamine-DARPP-32 signalling pathway may play an important role; (2) extinction learning modulates gene expression only in ventral striatum; (3) active food self-administration alters the expression of genes mainly involved in cell communication in ventral striatum; and (4) palatable food intake itself does not alter gene expression in the three brain areas analysed.

The operant schedule of reinforcement used to measure frustration was an adaptation of the behavioural paradigm previously validated (Burokas et al., 2012). This schedule produces high levels of responding and great resistance to extinction. In this situation, the elimination of reward delivery produces extremely high perseverative operant responding. As expected, frustration produced significant behavioural consequences since mice that underwent this frustration showed a significant subsequent increase in operant responding, as previously described (Burokas et al., 2012). Differential changes in gene expression were identified depending on the experimental group and the brain area analysed (Fig. 7). 
E. Martín-García

\section{Frustration}

Interestingly, most of the changes in gene expression that were similarly identified both in ventral striatum and frontal cortex were up-regulated in frustrated mice. Based on our analysis, these common changes in gene expression in frontal cortex and ventral striatum in frustrated mice point to transcripts with predominantly neuronal origin, especially in genes that show a higher over-expression (Fig. 5). This suggests that frustration is mainly ruled by neural mechanisms in agreement with human studies suggesting that omission of rewards produces behavioural changes processed by dopaminergic neurons in the ventral striatum, and emotional reactions involving activation of prefrontal cortex and anterior insula (Abler et al., 2005). The overexpression of these genes after the frustration event might be regulated by four transcription factors, Nkx2-5, Sox5 and Sry and Pdx1, identified in the enrichment analyses of transcription factor binding sites (Table 1). Nkx2-5 is involved in neuronal differentiation, Sox5 plays an important role in the specification of subcortically projecting axons and Sry localizes in midbrain dopaminergic neurons and participates in catecholamine metabolism (Pauwels et al., 2005; Leone et al., 2008; Czech et al., 2012), and Pdx1 is directly involved in food intake (Belgardt et al., 2008; Iskandar et al., 2010).

Interestingly, the dopamine-DARPP-32 feedback in cAMP signalling pathway was enriched in frontal cortex and ventral striatum genes in frustrated mice. We validated changes in frustrated mice in the expression of several genes of the dopamine-DARPP32 feedback in cAMP signalling pathway: Prkcb, Camk4 (up-regulated in ventral striatum), Crebbp and Plcb1 (up-regulated in frontal cortex). DARPP-32 is a substrate of cAMP-dependent protein kinase enriched in dopamine-innervated brain areas (Yger and Girault, 2011). Brain dopamine pathways modulate the behavioural responses to 
E. Martín-García

environmental stimuli and play central roles in obesity and addiction (Volkow and O'Brien, 2007; Tomasi and Volkow, 2013). The dopamine-DARPP-32 signalling pathway integrates glutamate and dopamine signals in midbrain dopaminergic neurons affecting fronto-striatal function and plasticity, and it has been related to several behavioural alterations including drug addiction (Albert et al., 2002; Svenningsson et al., 2005; Fernandez et al., 2006; Reuter et al., 2009; Mahajan et al., 2009). Both drugs of abuse and food reinforcement promote the nuclear accumulation of DARPP-32, which leads to nucleosomal responses (Stipanovich et al., 2008). Accordingly, DARPP32 mutated mice showed decreased motivation for food and altered behavioural effects of drugs of abuse (Stipanovich et al., 2008). A previous microarray study performed in mice with caloric restriction also identified enrichment of the dopamine receptor signalling and demonstrated that caloric restriction specifically increased DARPP-32 in the amygdala, and altered expression of two related genes, Ppm1l and Ppp2r5e, which are also altered in frustrated mice in our study (Yamamoto et al., 2009). DARPP-32 could be an interesting target for pharmacological interventions leading these behavioural alterations, with possibilities for modifying modulatory functions without altering vital mechanisms (Yger and Girault, 2011).

On the other hand, the CREBB signalling pathway in neurons was enriched in frontal cortex genes in frustrated mice. CREBB signalling is a key pathway in drug addiction since long lasting changes induced by drugs of abuse, learning and memory, converge in this pathway (Maldonado et al., 1996; Nestler, 2002). Indeed, learning, memory and drug addiction are modulated by the same neurotrophic factors, showing overlap in certain intracellular signalling cascades and parallel adaptations in neuronal morphology (Nestler, 2002). Both processes are accompanied by alterations in synaptic plasticity such as long-term potentiation (LTP) and long-term depression (LTD) at particular 
E. Martín-García

glutamatergic synapses (Kasanetz et al., 2010). Complex circuits involving the hippocampus, cerebral cortex, striatum and amygdala, influenced by CREBB signalling, are implicated both in addiction and learning and memory processes. Addiction could be considered as an aberrant learning with a strong association between the drug and the consequences of the reward (Kauer and Malenka, 2007). A better understanding of the molecular and cellular adaptations that occur in these neural circuits may lead to novel interventions to improve learning processes and develop novel therapeutic approaches for addiction and overeating.

Several key pathways involved in learning and memory processes in ventral striatum, such as synaptic LTP, glutamate receptor signalling and glutamate degradation, were enriched in frustrated mice. We validated in frustrated mice changes in gene expression of several genes involved in LTP, such as Plcb1, Prkcb, synaptic transmission, such as Camk4 and Nrxn1, as well as Crebbp, which is a key molecule in CREBB signalling. Synaptic plasticity, as studied by LTP and LTD, represents the ability of the brain to strengthen or depress neuronal circuits to maintain adaptive behavioural responses to changes in environmental contingencies (Goto et al., 2010; Neiman and Loewenstein, 2013). Drugs of abuse modify LTP and LTD in different areas of the mesocorticolimbic system that play a major role in motivation and addictive behaviour (Kauer and Malenka, 2007). Drug-induced alterations in LTP and LTD in ventral striatum and cerebral cortex have been proposed to play an important role in compulsive drug intake (Chen et al., 2008) and drug addiction (Kasanetz et al., 2010; Kasanetz et al., 2013).

\section{Extinction learning}

Extinction learning mice differed significantly from frustrated mice at both behavioural and gene expression level (Fig. 7). These mice did not show the frustrating responses because the behavioural consequences of the frustrated expected reward are minimized 
E. Martín-García

without the exposure to the CS. This allows to differentiate the behavioural consequences of the frustrated expected reward from the effects produced by an extinction-like procedure that is mimicked in this extinction learning group (Burokas et al., 2012). An illustrative model of the possible network involved in the behavioural responding revealed in the frustrated and extinction learning mice is depicted in Fig. 7. The behavioural control exerted by the frontal cortex on the operant responding is disrupted in the frustrated mice. Extinction learning mice have impaired reward expectation mediated by ventral striatum mechanisms. The exposure of all the experimental groups to a similar operant training could explain the absence of gene expression modification at the hippocampal level (Fig. 7). As expected, the extinction learning induced changes in gene expression only in ventral striatum, in agreement with the differences of motivation and reward expectation driven by the CS (Fig.7). In contrast with frustrated mice, the dopamine-DARPP-32 signalling pathway was not enriched in extinction learning mice. In addition, the ERK5 signalling pathway was enriched in ventral striatum only in extinction learning mice, which has an important role in hippocampus-dependent memory, mainly contextual memory (Pan et al., 2013). Similarly, the JAK signalling pathway that is involved in drug addiction and mediates chronic cocaine effects on the VTA dopaminergic neurons (Berhow et al., 1996), was also found to be enriched in the ventral striatum of extinction learning mice and this change was validated. Furthermore, the enriched CNTF signalling pathway is interestingly involved in food intake since CNTF administration reduced food intake and body weight in obese (Stefater et al., 2012). All those enriched pathways involved in addiction, memory and food intake may play an important role in the neuronal adaptations and behavioural outcomes related to this extinction learning. 
E. Martín-García

\section{Palatable food operant training}

Ventral striatum was the only brain region that showed transcriptional changes induced by operant training to obtain palatable food. Most of the genes showing altered expression as a consequence of palatable food seeking behaviour were involved in cell communication, a key function for the establishment of new synapses, and neuronal remodeling processes essential for learning and memory. Among the pathways enriched by palatable seeking, it is worth to mention those involved in neuronal adaptive changes, such as "Neurotrophin signalling pathway" and "MAPK signalling pathways". Interestingly, long-term exposure to palatable food itself did not produce differential effects on gene expression changes, which does not allow to identify differences due to palatable food intake under our experimental conditions.

Several limitations should be taken into account in the present study: i) the heterogeneity of the samples regarding individual differences in behavioural responses, ii) the use of pooled samples, that was performed to obtain sufficient RNA from tissue samples of small size and to reduce the number of replicas in the microarray, iii) the small fold change in gene fluctuations that could limit detection of differences in lowly expressed genes. Gene expression profile was assessed $20 \mathrm{~min}$ after the last progressive ratio session, and gene expression changes at this time-point are therefore likely to reflect an acute effect rather than long-term changes. Therefore, important long-term changes in gene expression, such as those involved in synaptic plasticity and remodeling or other still unknown genes triggering long-term changes, could be missed out in our experiment design of frustrating behaviour in favour of acute expression changes. In this sense, the lack of gene expression changes in the hippocampus may be explained by our experimental conditions that prioritized acute effects of frustration. In contrast, other studies prioritizing long-term changes have revealed gene expression 
E. Martín-García

modifications in this brain region after pharmacological and/or operant training manipulations (Krasnova et al., 2008; Fernandez-Castillo et al., 2012). Specific gene expression changes were detected in particular brain areas after a unique behavioral manipulation. In frontal cortex, differences were only detected between positive control and frustrated mice (Fig. 7). An inhibitory control of the motivation exerted by frontal cortex should occur in positive control mice after the reward acquisition, whereas this inhibitory control would not appear in frustrated mice that did not receive the reward. In contrast, differences in the striatum were identified between the extinction learning group and the other two groups, while no changes in gene expression were seen between frustrated animals and positive controls (Fig. 7). This dramatic change selectively promoted by omission of the secondary reinforcer, the cue light, reveals the relevance of the predictive value of this stimulus.

In conclusion, the mechanisms underlying frustrated behaviour seem to involve mainly neuronal circuits pointing to the dopamine-DARPP-32 signalling pathway as a common target in frontal cortex and ventral striatum. In contrast, extinction learning does not involve dopamine-DARPP-32 signalling and the changes in gene expression are restricted to the ventral striatum. Active palatable food seeking also involves specific changes in ventral striatum and differences due to palatable food intake could not be identified. The dopamine-DARPP-32 signalling could play an important role in the loss of control and might represent a key common mechanism in the loss of behavioural control that appears in obesity and drug addiction raising the interest of this target for potential pharmacological interventions. Further studies should be performed to explore the role of dopamine-DARPP-32 signalling in these complex behavioural processes. 
E. Martín-García

\section{Acknowledgements}

This work was supported by the Spanish 'Instituto de Salud Carlos III' (RTA, RD06/001/001 and PI11/01629), the Spanish 'Ministerio de Ciencia e Innovación' (SAF2007-64062 and SAF2012-33484), the Spanish 'Ministerio de Sanidad y Política Social' (Plan Nacional Sobre Drogas, no. 2009/022 and 2009/026), the Catalan Government (2009-SGR-00131 and 2014-SGR-0932), the ICREA Foundation (ICREA Academia-2008). A.B. was supported by a FI predoctoral fellowship of the Catalan Government, J. G-C. was supported by a "Juan de la Cierva" post-doctoral fellowship from the Spanish 'Ministerio de Ciencia e Innovación', E. M-G. was supported by a "Sara Borrell" post-doctoral fellowship from the Spanish 'Instituto de Salud Carlos III', NF-C was supported by a contract from the Biomedical Network Research Centre on Rare Diseases (CIBERER) and MR was supported by a "Miguel i Servet" contract the Spanish 'Instituto de Salud Carlos III'. Partial support from FEDER funds is also acknowledged.

\section{Authors contribution}

E. M.-G., A.B. and J. G.-C. conducted the behavioural studies and participated in the interpretation and manuscript writing. N. F.-C. conducted the microarrays expression study and participated in the interpretation and manuscript writing. C. S.-M. performed the RNA isolation. M.R., B.C. and R.M. participated in the experimental design, the supervision, interpretation and manuscript writing and funded the project. 
E. Martín-García

\section{References}

Abler B, Walter H and Erk S (2005) Neural Correlates of Frustration. Neuroreport 16:669-672.

Albert KA, Hemmings HC, Jr., Adamo AI, Potkin SG, Akbarian S, Sandman CA, Cotman CW, Bunney WE, Jr. and Greengard P (2002) Evidence for Decreased DARPP32 in the Prefrontal Cortex of Patients With Schizophrenia. Arch Gen Psychiatry 59:705-712.

Amsel A (1958) The Role of Frustrative Nonreward in Noncontinuous Reward Situations. Psychol Bull 55: 102-119.

Belgardt BF, Husch A, Rother E, Ernst MB, Wunderlich FT, Hampel B, Klockener T, Alessi D, Kloppenburg P and Bruning JC (2008) PDK1 Deficiency in POMC-Expressing Cells Reveals FOXO1-Dependent and -Independent Pathways in Control of Energy Homeostasis and Stress Response. Cell Metab 7:291-301.

Berhow MT, Hiroi N, Kobierski LA, Hyman SE and Nestler EJ (1996) Influence of Cocaine on the JAK-STAT Pathway in the Mesolimbic Dopamine System. $J$ Neurosci 16:8019-8026.

Burokas A, Gutierrez-Cuesta J, Martin-Garcia E and Maldonado R (2012) Operant Model of Frustrated Expected Reward in Mice. Addict Biol 17:770-782.

Chen BT, Bowers MS, Martin M, Hopf FW, Guillory AM, Carelli RM, Chou JK and Bonci A (2008) Cocaine but Not Natural Reward Self-Administration nor Passive Cocaine Infusion Produces Persistent LTP in the VTA. Neuron 59:288-297.

Cifani C, Polidori C, Melotto S, Ciccocioppo R and Massi M (2009a) A Preclinical Model of Binge Eating Elicited by Yo-Yo Dieting and Stressful Exposure to Food: Effect of Sibutramine, Fluoxetine, Topiramate, and Midazolam. Psychopharmacology (Berl) 204:113-125.

Cifani C, Zanoncelli A, Tessari M, Righetti C, Di FC, Ciccocioppo R, Massi M and Melotto S (2009b) Pre-Exposure to Environmental Cues Predictive of Food Availability Elicits Hypothalamic-Pituitary-Adrenal Axis Activation and Increases Operant Responding for Food in Female Rats. Addict Biol 14:397-407.

Czech DP, Lee J, Sim H, Parish CL, Vilain E and Harley VR (2012) The Human Testis-Determining Factor SRY Localizes in Midbrain Dopamine Neurons and Regulates Multiple Components of Catecholamine Synthesis and Metabolism. J Neurochem 122:260-271.

Everitt BJ, Belin D, Economidou D, Pelloux Y, Dalley JW and Robbins TW (2008) Review. Neural Mechanisms Underlying the Vulnerability to Develop Compulsive Drug-Seeking Habits and Addiction. Philos Trans R Soc Lond B Biol Sci 363:3125-3135.

Fernandez E, Schiappa R, Girault JA and Le NN (2006) DARPP-32 Is a Robust Integrator of Dopamine and Glutamate Signals. PLoS Comput Biol 2:e176. 
Fernandez-Castillo N, Orejarena MJ, Ribases M, Blanco E, Casas M, Robledo P, Maldonado R and Cormand B (2012) Active and Passive MDMA ('Ecstasy') Intake Induces Differential Transcriptional Changes in the Mouse Brain. Genes Brain Behav 11:38-51.

Goto Y, Yang CR and Otani S (2010) Functional and Dysfunctional Synaptic Plasticity in Prefrontal Cortex: Roles in Psychiatric Disorders. Biol Psychiatry 67:199207.

Haber SN, Kim KS, Mailly P and Calzavara R (2006) Reward-Related Cortical Inputs Define a Large Striatal Region in Primates That Interface With Associative Cortical Connections, Providing a Substrate for Incentive-Based Learning. J Neurosci 26:8368-8376.

Hamer D (2002) Genetics. Rethinking Behavior Genetics. Science 298:71-72.

Henna E, Zilberman ML, Gentil V and Gorenstein C (2008) Validity of a Frustration-Induction Procedure. Rev Bras Psiquiatr 30:47-49.

Ho Sui SJ, Mortimer JR, Arenillas DJ, Brumm J, Walsh CJ, Kennedy BP and Wasserman WW (2005) OPOSSUM: Identification of Over-Represented Transcription Factor Binding Sites in Co-Expressed Genes. Nucleic Acids Res 33:3154-3164.

Iskandar K, Cao Y, Hayashi Y, Nakata M, Takano E, Yada T, Zhang C, Ogawa W, Oki M, Chua S Jr, Itoh H, Noda T, Kasuga M and Nakae J (2010) PDK-1/FoxO1 Pathway in POMC Neurons Regulates Pomc Expression and Food Intake. Am J Physiol Endocrinol Metab 298:E787-E798.

Kalivas PW (2004) Glutamate Systems in Cocaine Addiction. Curr Opin Pharmacol 4:23-29.

Kasanetz F, Lafourcade M, roche-Gamonet V, Revest JM, Berson N, Balado E, Fiancette JF, Renault P, Piazza PV and Manzoni OJ (2013) Prefrontal Synaptic Markers of Cocaine Addiction-Like Behavior in Rats. Mol Psychiatry 18:729-737.

Kasanetz F, roche-Gamonet V, Berson N, Balado E, Lafourcade M, Manzoni O and Piazza PV (2010) Transition to Addiction Is Associated With a Persistent Impairment in Synaptic Plasticity. Science 328:1709-1712.

Kauer JA and Malenka RC (2007) Synaptic Plasticity and Addiction. Nat Rev Neurosci 8:844-858.

Krasnova IN, Li SM, Wood WH, McCoy MT, Prabhu VV, Becker KG, Katz JL and Cadet JL (2008) Transcriptional Responses to Reinforcing Effects of Cocaine in the Rat Hippocampus and Cortex. Genes Brain Behav 7:193-202.

Leone DP, Srinivasan K, Chen B, Alcamo E and McConnell SK (2008) The Determination of Projection Neuron Identity in the Developing Cerebral Cortex. Curr Opin Neurobiol 18:28-35.

Mahajan SD, Aalinkeel R, Reynolds JL, Nair BB, Sykes DE, Hu Z, Bonoiu A, Ding H, Prasad PN and Schwartz SA (2009) Therapeutic Targeting of "DARPP-32": a 
Key Signaling Molecule in the Dopiminergic Pathway for the Treatment of Opiate Addiction. Int Rev Neurobiol 88:199-222.:-2.

Maldonado R, Blendy JA, Tzavara E, Gass P, Roques BP, Hanoune J and Schutz G (1996) Reduction of Morphine Abstinence in Mice With a Mutation in the Gene Encoding CREB. Science 273:657-659.

Neiman T and Loewenstein Y (2013) Covariance-Based Synaptic Plasticity in an Attractor Network Model Accounts for Fast Adaptation in Free Operant Learning. $J$ Neurosci 33:1521-1534.

Nestler EJ (2002) Common Molecular and Cellular Substrates of Addiction and Memory. Neurobiol Learn Mem 78:637-647.

Pan YW, Storm DR and Xia Z (2013) Role of Adult Neurogenesis in Hippocampus-Dependent Memory, Contextual Fear Extinction and Remote Contextual Memory: New Insights From ERK5 MAP Kinase. Neurobiol Learn Mem10.

Pauwels S, Barone R, Walrand S, Borson-Chazot F, Valkema R, Kvols LK, Krenning EP and Jamar F (2005) Practical Dosimetry of Peptide Receptor Radionuclide Therapy With (90)Y-Labeled Somatostatin Analogs. J Nucl Med 46 Suppl 1:92S8S.:92S-98S.

Paxinos G and Franklin KBJ (1997) The Mouse Brain in Stereotaxic Coordinates. Academic, San Diego.

Reuter M, Weber B, Fiebach CJ, Elger C and Montag C (2009) The Biological Basis of Anger: Associations With the Gene Coding for DARPP-32 (PPP1R1B) and With Amygdala Volume. Behav Brain Res 202:179-183.

Sibille E, Arango V, Joeyen-Waldorf J, Wang Y, Leman S, Surget A, Belzung C, Mann JJ and Lewis DA (2008) Large-Scale Estimates of Cellular Origins of MRNAs: Enhancing the Yield of Transcriptome Analyses. J Neurosci Methods 167:198-206.

Stefater MA, MacLennan AJ, Lee N, Patterson CM, Haller A, Sorrell J, Myers M, Woods SC and Seeley RJ (2012) The Anorectic Effect of CNTF Does Not Require Action in Leptin-Responsive Neurons. Endocrinology 153:2647-2654.

Stipanovich A, Valjent E, Matamales M, Nishi A, Ahn JH, Maroteaux M, Bertran-Gonzalez J, Brami-Cherrier K, Enslen H, Corbille AG, Filhol O, Nairn AC, Greengard P, Herve D and Girault JA (2008) A Phosphatase Cascade by Which Rewarding Stimuli Control Nucleosomal Response. Nature 453:879-884.

Svenningsson P, Nairn AC and Greengard P (2005) DARPP-32 Mediates the Actions of Multiple Drugs of Abuse. AAPS J 7:E353-E360.

Tomasi D and Volkow ND (2013) Striatocortical Pathway Dysfunction in Addiction and Obesity: Differences and Similarities. Crit Rev Biochem Mol Biol 48:119.

Volkow ND and Fowler JS (2000) Addiction, a Disease of Compulsion and Drive: Involvement of the Orbitofrontal Cortex. Cereb Cortex 10:318-325. 
Volkow ND, Fowler JS and Wang GJ (2003) The Addicted Human Brain: Insights From Imaging Studies. J Clin Invest 111:1444-1451.

Volkow ND and O'Brien CP (2007) Issues for DSM-V: Should Obesity Be Included As a Brain Disorder? Am J Psychiatry 164:708-710.

Yamamoto Y, Tanahashi T, Kawai T, Chikahisa S, Katsuura S, Nishida K, Teshima-Kondo S, Sei H and Rokutan K (2009) Changes in Behavior and Gene Expression Induced by Caloric Restriction in C57BL/6 Mice. Physiol Genomics 39:227235.

Yger M and Girault JA (2011) DARPP-32, Jack of All Trades... Master of Which? Front Behav Neurosci 5:56.:56. 
E. Martín-García

\section{Figure legends}

Figure 1. Experimental design. Experimental sequence and groups included to reveal the behavioural consequences of the unexpected delivery of a natural reward (palatable food). CS, Conditioned stimulus; FR, Fixed ratio; PR, Progressive ratio.

Figure 2. Acquisition of operant behaviour to obtain palatable food and active lever-presses after the frustrated expected reward. (a) Mean number of active leverpresses during FR1, FR5, FR10 and PR schedule of reinforcement to obtain chocolate flavoured-pellets in frustration, positive control, extinction learning, yoked and negative control groups. (b) Mean number of active lever-presses during 10 additional min after end-point 150. (c) Representative patterns of active and inactive lever-presses during the 10 additional min after the end-point 150 for the different groups (frustration, positive control, extinction learning). Each vertical line represents one active or inactive leverpress. The horizontal line represents the 10 additional min after the end-point 150; the upper pattern corresponds to the active and the lower to the inactive lever-presses responses. Data are expressed as mean $\pm \operatorname{SEM}(\mathrm{n}=9$ per group). $\star p<0.05$ vs. positive control group (Newman-Keuls).

Figure 3. Gene expression changes caused by food intake frustration or extinction learning. (a) Venn Diagrams of genes differentially expressed in each comparison for the three brain areas. (b) Frustration specific changes. On the left, total number of genes that are up-regulated or down-regulated only in frustrated mice in frontal cortex, ventral striatum and in both areas. On the right, canonical pathway enrichment analysis using "Ingenuity Pathway Analysis (IPA)" of the genes differentially expressed only due to frustration behaviour in the frontal cortex and in ventral striatum. Note the common 
enrichment of the Dopamine-DARPP-32 signalling pathway (highlighted with a red frame). (c) Extinction learning specific changes. On the left, total number of genes that are up-regulated or down-regulated only in extinction learning mice. On the right, canonical pathway enrichment analysis of the genes differentially expressed only due to extinction learning. The significance of canonical pathways was determined by IPA's default threshold $[-\log (p$-value $)>1.3]$ corresponding to Fisher's exact test $p$-value $=0.05$ and indicated by the yellow line. The yellow squares indicate the ratio between the number of genes in a given pathway that meet cut-off criteria and the total number of genes that make up that pathway.

Figure 4. Dopamine-DARPP-32 feedback in cAMP signalling in frustration-like behaviour. The green and red nodes in this enriched canonical pathway indicate the down-regulated and up-regulated genes in the frustrated mice in ventral striatum and the red stars indicate up-regulated genes in the frustrated mice in frontal cortex.

Figure 5. Glial/neuronal enrichment of altered gene expression in frontal cortex in the frustration model. (a) Transcripts differentially expressed $(n=116)$ in frontal cortex between frustrated and positive control mice and (b) transcripts differentially expressed $(n=47)$ in the frustrated mice but common in frontal cortex and ventral striatum. Left panel: Transcripts are organized vertically according to the extent of altered gene expression. Up and down arrows indicate up and down-regulation of gene expression, separated by a purple bar. Colour overlay indicates the cellular origin of the transcript: orange $\sim$ glial origin (white matter/grey matter: WM/GM $>1.5$ ), blue $\sim$ neuronal origin $(\mathrm{WM} / \mathrm{GM}<-1.5)$ and white both cellular populations $(-1.5>\mathrm{WM} / \mathrm{GM}<1.5)$ (Sibille et al., 
E. Martín-García

2008). Right panel: percentage of transcripts of each cell type origin. Note the apparent increased representation of neuronal expression in both cases.

Figure 6. Gene expression changes caused by food self-administration reinforced learning. (a) Venn diagrams of genes differentially expressed in each comparison for the three brain areas. (b) Number of genes that are up-regulated or down-regulated only in mice that learned to self-administer the food (positive control), common in the comparison of positive control - yoked and positive control - negative control. (c) Cell communication enriched genes in food self-administration reinforced learning. Heatmap showing the level of expression in the microarray of the 48 genes identified in the GO:0007154 cell communication $(\operatorname{adjP}=8.2$ e-3). For each experimental group the three replicates are shown.

Figure 7. Theoretical model of frustration and extinction learning effects in mice behaviour and correlation with gene expression changes. (a) Model proposing a network of the main interacting circuits involved in addiction that may underlie frustration and extinction learning situations (adapted from (Volkow et al., 2003)). In positive control mice, the conditioned stimulus (CS) triggers an increased motivation for reward seeking (food) and also increases reward expectation in the ventral striatum (VS), leading to lever press. After the reward acquisition, there is an inhibitory control for the motivation exerted by the frontal cortex (FC). Frustrated mice do not receive a reward, and so no inhibition of the reward seeking is driven by FC, increasing motivation and reward expectation, and the number of lever-presses. Extinction learning mice behaviour is not driven by the CS, and the motivation for reward seeking therefore is not increased leading to a decreased expectation mediated by VS mechanisms. (b) 
Gene expression changes in each key brain region: hippocampus (HPC), VS and FC. No differences in HPC were detected since mice were exposed to the same training of active food self-administration. Those differences at VS and FC activation could lead to gene expression changes between each group, but they are not detectable in all comparisons. In VS, the most different group is extinction learning, without presence of cue-induced food-seeking, motivation and reward expectation, and so differences are only detected between this group and frustrated and positive control mice. In FC, differences in gene expression are only detected between frustrated and positive control, which are expected to have opposite effects in this brain region. 
Table 1. Over-representation of transcription factor binding sites in frustration. Predicted targets for transcription factors in common in up-regulated genes in frustrated mice in frontal cortex, ventral striatum and genes common in both areas.

\begin{tabular}{|c|c|c|c|c|c|c|c|c|c|}
\hline & \multicolumn{9}{|c|}{ Up-regulated } \\
\hline & \multicolumn{3}{|c|}{ Frontal cortex } & \multicolumn{3}{|c|}{ Frontal cortex } & \multicolumn{3}{|c|}{ Common changes in both areas } \\
\hline & $\begin{array}{l}\text { Target gene } \\
\text { hits/ non hits }\end{array}$ & Z-score & $\begin{array}{l}\text { Fisher } \\
\text { score }\end{array}$ & $\begin{array}{l}\text { Target gene } \\
\text { hits/ non hits }\end{array}$ & Z-score & $\begin{array}{l}\text { Fisher } \\
\text { score }\end{array}$ & $\begin{array}{l}\text { Target gene } \\
\text { hits/ non hits }\end{array}$ & Z-score & $\begin{array}{l}\text { Fisher } \\
\text { score }\end{array}$ \\
\hline Nkx2-5 & $90 / 4$ & 20.34 & $3.1 e-5$ & 482 / 44 & 42.84 & $1.7 e-11$ & $37 / 2$ & 7.76 & $1.4 \mathrm{e}-2$ \\
\hline SRY & $87 / 7$ & 22.16 & $1.1 \mathrm{e}-6$ & $462 / 64$ & 41.12 & $3.7 e-17$ & $35 / 4$ & 12.01 & $8.4 \mathrm{e}-3$ \\
\hline Sox5 & $88 / 6$ & 19.11 & $1.3 e-6$ & $473 / 53$ & 37.83 & $5.8 \mathrm{e}-19$ & $36 / 3$ & 8.53 & $4.5 \mathrm{e}-3$ \\
\hline$P d x 1$ & $89 / 5$ & 22.81 & $3.2 e-5$ & $485 / 41$ & 31.63 & $1.5 \mathrm{e}-15$ & $36 / 3$ & 7.61 & $2.7 \mathrm{e}-2$ \\
\hline
\end{tabular}




\section{E. Martín-García}

Table 2. Changes in gene expression induced by frustration on qRT-PCR validation of microarray data of genes differentially expressed in frustrated mice. (a) Changes in frontal cortex in the comparison between frustrated vs positive control. (b) changes in ventral striatum between frustrated vs extinction learning.

a)

\begin{tabular}{|c|c|c|c|c|}
\hline \multirow{3}{*}{\multicolumn{2}{|c|}{ Frontal Cortex }} & \multicolumn{3}{|c|}{ Frustrated vs Positive control } \\
\hline & & \multicolumn{2}{|c|}{ Microarray } & \multirow{2}{*}{$\begin{array}{c}\text { qRT-PCR } \\
\text { Fold Change }\end{array}$} \\
\hline & & Fold Change & $\begin{array}{c}\text { P-value } \\
\text { (Adj P value) }\end{array}$ & \\
\hline Crebbp & CREB binding protein & 1.61 & $3.3 \mathrm{e}-5(1.6 \mathrm{e}-2)$ & $1.3 \mathrm{a}$ \\
\hline Cnr1 & Cannabinoid receptor 1 (brain) & 1.99 & 2.9 e-5 (1.6 e-2) & $1.4 \mathrm{a}$ \\
\hline Plcb1 & Phospholipase C, beta 1 & 2.03 & $2.6 \mathrm{e}-5(1.6 \mathrm{e}-2)$ & $1.2 \mathrm{a}$ \\
\hline Nrxn1 & Neurexin 1 & 1.49 & $3.2 \mathrm{e}-4(5 \mathrm{e}-2)$ & $1.2^{\mathrm{a}}$ \\
\hline Jak1 & Janus kinase 2 & 1.48 & $1.0 \mathrm{e}-5(1 \mathrm{e}-2)$ & $1.2 \mathrm{a}$ \\
\hline
\end{tabular}

b)

\begin{tabular}{|c|c|c|c|c|}
\hline \multirow{3}{*}{\multicolumn{2}{|c|}{ Ventral Striatum }} & \multicolumn{3}{|c|}{ Frustrated vs Extinction learning } \\
\hline & & \multicolumn{2}{|c|}{ Microarray } & \multirow{2}{*}{$\begin{array}{c}\text { qRT-PCR } \\
\text { Fold Change }\end{array}$} \\
\hline & & Fold Change & $\begin{array}{c}\text { P-value } \\
\text { (Adj P value) }\end{array}$ & \\
\hline Camk4 & Calcium/calmodulin-dependent protein kinase IV & 2.00 & 4.8 e-5 $(4.7$ e-3) & $1.3^{a}$ \\
\hline Kalrn & Kalirin, RhoGEF kinase & 1.93 & 1.5 e-5 (2.9 e-3) & $1.3^{a}$ \\
\hline Rph3a & Rabphilin, 3A & 1.89 & 1.2 e-4 (7.3 e-3) & NS \\
\hline Prkcb & Protein Kinase C, beta & 2.21 & 1.9 e-3 (3.4 e-2) & $1.5 \mathrm{a}$ \\
\hline Gprin3 b & GPRIN family membersse 2 & 1.88 & 2.9 e-5 (3.8 e-3) & $1.2 \mathrm{a}$ \\
\hline
\end{tabular}

${ }^{a}$ p-value $<0.05$; normalized to Gadph.

${ }^{\mathrm{b}}$ Genes with differential expression following the same direction in two probe sets in the microarray analysis. The smallest absolute fold change is shown.

NS, not significant 
Table 3: Changes in gene expression induced by extinction learning: qRT-PCR validation of microarray data of genes differentially expressed common between extinction learning-positive control and extinction learning-frustrated comparisons in Ventral Striatum.

\begin{tabular}{|c|c|c|c|c|c|c|c|}
\hline & & \multicolumn{3}{|c|}{$\begin{array}{l}\text { Extinction learning } \\
\text { vs Positive control }\end{array}$} & \multicolumn{3}{|c|}{$\begin{array}{l}\text { Extinction learning } \\
\text { vs Frustrated }\end{array}$} \\
\hline & & & croarray & qRT- & & croarray & qRT- \\
\hline \multicolumn{2}{|c|}{ Ventral Striatum } & $\begin{array}{l}\text { Fold } \\
\text { Change }\end{array}$ & $\begin{array}{l}\text { P-value } \\
\text { (Adj P value) }\end{array}$ & $\begin{array}{l}\text { Fold } \\
\text { Change }\end{array}$ & $\begin{array}{l}\text { Fold } \\
\text { Change }\end{array}$ & $\begin{array}{c}\text { P-value } \\
\text { (Adj P value) }\end{array}$ & $\begin{array}{l}\text { Fold } \\
\text { Change }\end{array}$ \\
\hline Crebbp & CREB binding protein & -2.23 & $6.5 e-6(2 e-3)$ & $-1.3 \mathrm{a}$ & -2.86 & 6.7 e-5 (2.2 e-2) & $-1.8 \mathrm{a}$ \\
\hline Cnr1 & Cannabinoid receptor 1 (brain) & -1.87 & $2.5 e-6(1.4 \mathrm{e}-3)$ & $-1.3 \mathrm{a}$ & -2.25 & 2.9 e-5 (1.9 e-2) & -1.5 a \\
\hline Plcb1 & Phospholipase $\mathrm{C}$, beta 1 & -2.18 & 7.3 e-6 (2 e-3) & $-1.2 \mathrm{a}$ & -3.10 & $1.6 \mathrm{e}-4(3 \mathrm{e}-2)$ & $-1.5^{a}$ \\
\hline Nrxn1 & Neurexin 1 & -2.63 & 8.5 e-5(6.2 e-4) & -1.3 a & -2.38 & 3.5 e-5 (1.9 e-2) & -1.4 a \\
\hline Jak1 & Janus kinase 2 & -1.99 & 1.5 e-5 (2.8 e-3) & $-1.2^{a}$ & -2.08 & 2.6 e-5 (1.9 e-2) & $-1.3^{a}$ \\
\hline Grit & Rho GTPase-activating protein & -1.58 & $1.3 e-5(2.6 e-3)$ & -1.3 a & -1.85 & 1.5 e-4 (2.9 e-2) & NS \\
\hline
\end{tabular}

${ }^{\text {a }}$ p-value $<0.05$; normalized to Gapdh

NS, not significant 
E. Martín-García

\section{Supporting Information}

Additional supporting information can be found in the online version of this article:

Table S1. Operant responding maintained by chocolate during acquisition in the frustrated, extinction learning and positive control groups.

Table S2. Operant responding and operant responding rates (lever-presses/min) maintained by chocolate during 10 additional min after achieving the end-point 150 in the frustrated, extinction learning and positive control groups.

Table S3: Differentially expressed genes in frontal cortex only between frustrated and positive control mice after applying corrections for multiple testing (5\% FDR).

Table S4: Differentially expressed genes in ventral striatum only between frustrated and extinction learning mice after applying multiple testing corrections (5\% FDR).

Table S5: Differentially expressed genes in ventral striatum that are common between the comparisons extinction learning vs frustrated and extinction learning vs positive control after applying multiple testing corrections (5\% FDR).

Table S6: Differentially expressed genes in ventral striatum that are common between the comparisons positive control vs yoked and positive control vs negative control after applying multiple testing corrections (10\% FDR). 


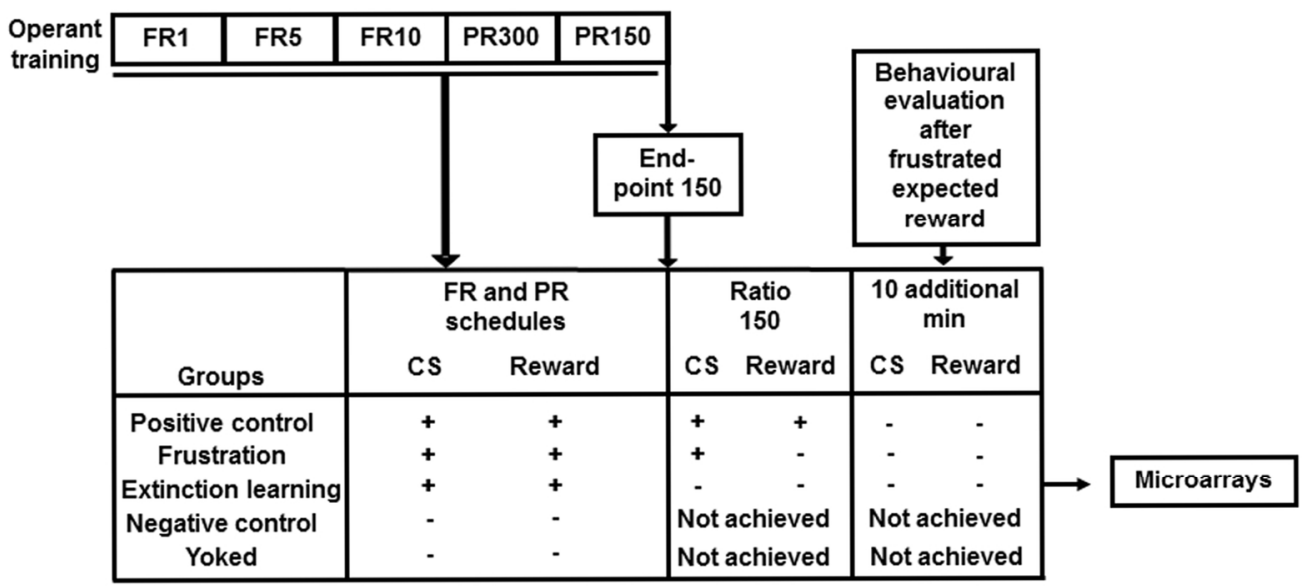

Figure 1. Experimental design. Experimental sequence and groups included to reveal the behavioural consequences of the unexpected delivery of a natural reward (palatable food). CS, Conditioned stimulus; FR, Fixed ratio; PR, Progressive ratio. $129 \times 64 \mathrm{~mm}(300 \times 300 \mathrm{DPI})$ 

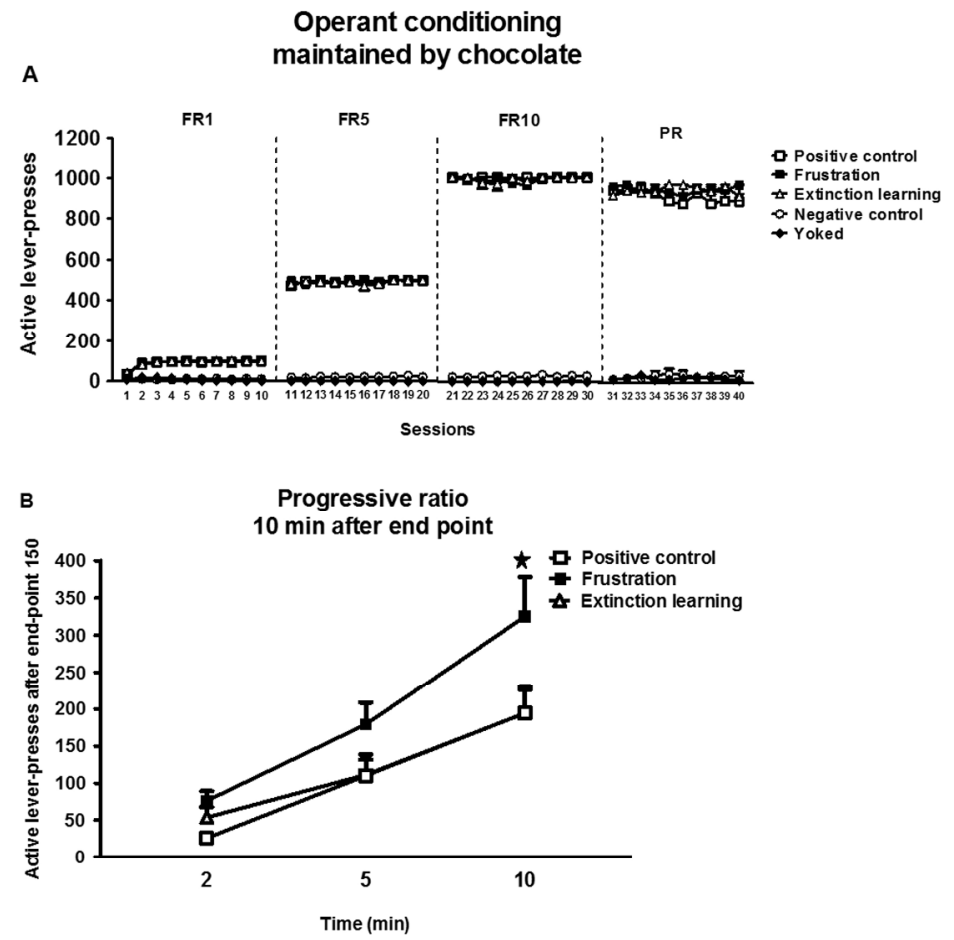

C
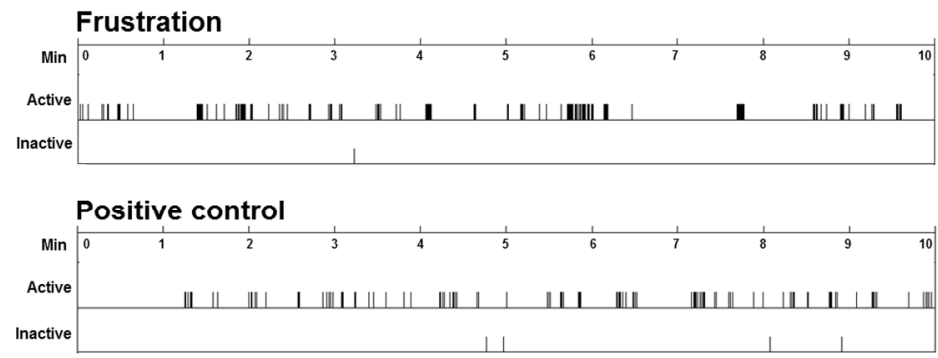

ExtInction learning

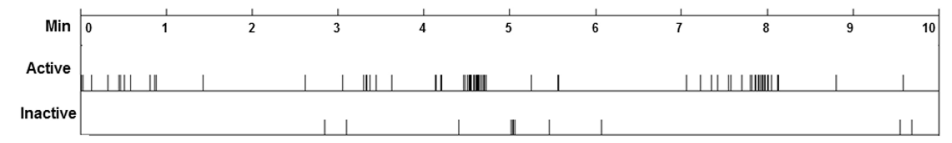

Figure 2. Acquisition of operant behaviour to obtain palatable food and active lever-presses after the frustrated expected reward. (a) Mean number of active lever-presses during FR1, FR5, FR10 and PR schedule of reinforcement to obtain chocolate flavoured-pellets in frustration, positive control, extinction learning, yoked and negative control groups. (b) Mean number of active lever-presses during 10 additional min after end-point 150. (c) Representative patterns of active and inactive lever-presses during the 10 additional min after the end-point 150 for the different groups (frustration, positive control, extinction learning). Each vertical line represents one active or inactive lever-press. The horizontal line represents the 10 additional min after the end-point 150; the upper pattern corresponds to the active and the lower to the inactive lever-presses responses. Data are expressed as mean $\pm \operatorname{SEM}(n=9$ per group). $\mid * p<0.05$ vs. positive control group (Newman-Keuls).

$$
236 \times 372 \mathrm{~mm}(300 \times 300 \mathrm{DPI})
$$


A

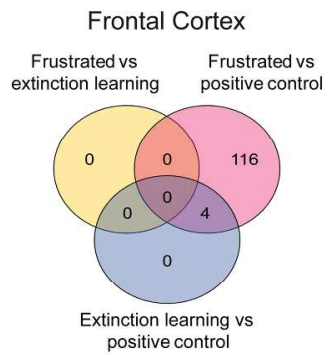

Ventral Striatum

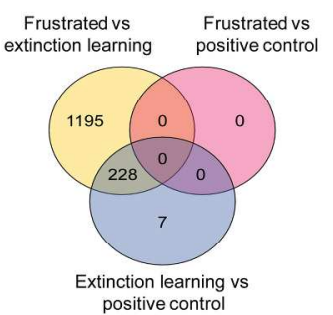

Hippocampus

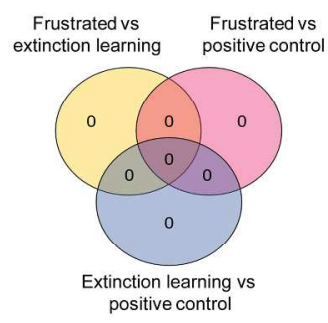

B Frustration specific changes

\begin{tabular}{|c|c|c|c|}
\cline { 2 - 4 } \multicolumn{1}{c|}{} & \multicolumn{3}{c|}{ Number of genes } \\
\cline { 2 - 4 } \multicolumn{1}{c|}{} & $\mathbf{t}$ & $\downarrow$ & Total \\
\hline Frontal cortex & 112 & 4 & 116 \\
\hline $\begin{array}{c}\text { Ventral } \\
\text { striatum }\end{array}$ & 804 & 391 & 1195 \\
\hline $\begin{array}{c}\text { Common } \\
\text { in both areas }\end{array}$ & 47 & - & 47 \\
\hline
\end{tabular}

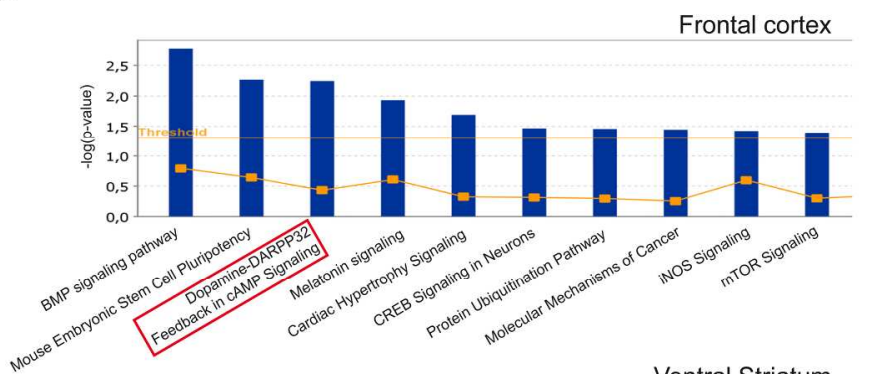

veratsisum

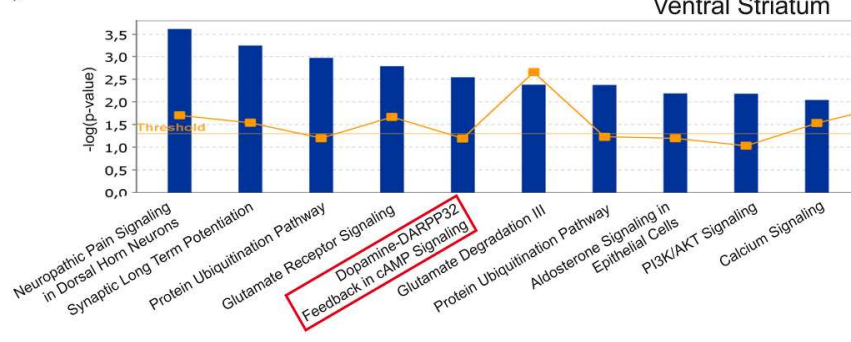

C Extinction learning specific changes

\begin{tabular}{|c|c|c|c|}
\cline { 2 - 4 } \multicolumn{1}{c|}{} & \multicolumn{3}{c|}{ Number of genes } \\
\cline { 2 - 4 } \multicolumn{1}{c|}{} & $\mathbf{1}$ & $\downarrow$ & Total \\
\hline Frontal cortex & - & - & - \\
\hline $\begin{array}{c}\text { Ventral } \\
\text { striatum }\end{array}$ & 59 & 169 & 228 \\
\hline $\begin{array}{c}\text { Common } \\
\text { in both areas }\end{array}$ & - & - & - \\
\hline
\end{tabular}

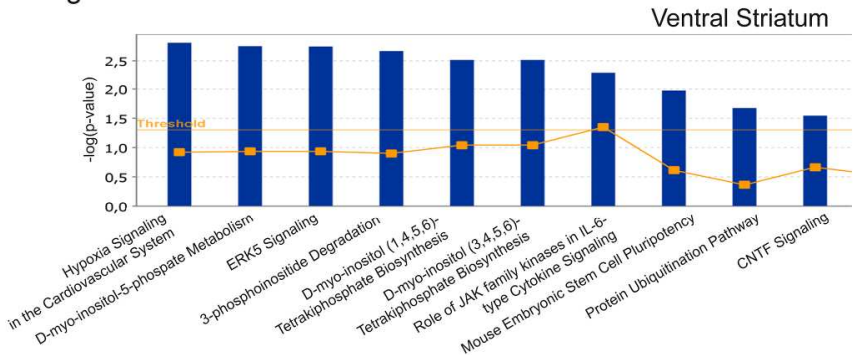

Figure 3. Gene expression changes caused by food intake frustration or extinction learning. (a) Venn Diagrams of genes differentially expressed in each comparison for the three brain areas. (b) Frustration specific changes. On the left, total number of genes that are up-regulated or down-regulated only in frustrated mice in frontal cortex, ventral striatum and in both areas. On the right, canonical pathway enrichment analysis using "Ingenuity Pathway Analysis (IPA)" of the genes differentially expressed only due to frustration behaviour in the frontal cortex and in ventral striatum. Note the common enrichment of the Dopamine-DARPP-32 signalling pathway (highlighted with a red frame). (c) Extinction learning specific changes. On the left, total number of genes that are up-regulated or down-regulated only in extinction learning mice. On the right, canonical pathway enrichment analysis of the genes differentially expressed only due to extinction learning. The significance of canonical pathways was determined by IPA's default threshold [-log ( $p$-value) $>1.3]$ corresponding to Fisher's exact test $p$-value $=0.05$ and indicated by the yellow line. The yellow squares indicate the ratio between the number of genes in a given pathway that meet cut-off criteria and the total number of genes that make up that pathway. 
$219 \times 268 \mathrm{~mm}(300 \times 300$ DPI) 


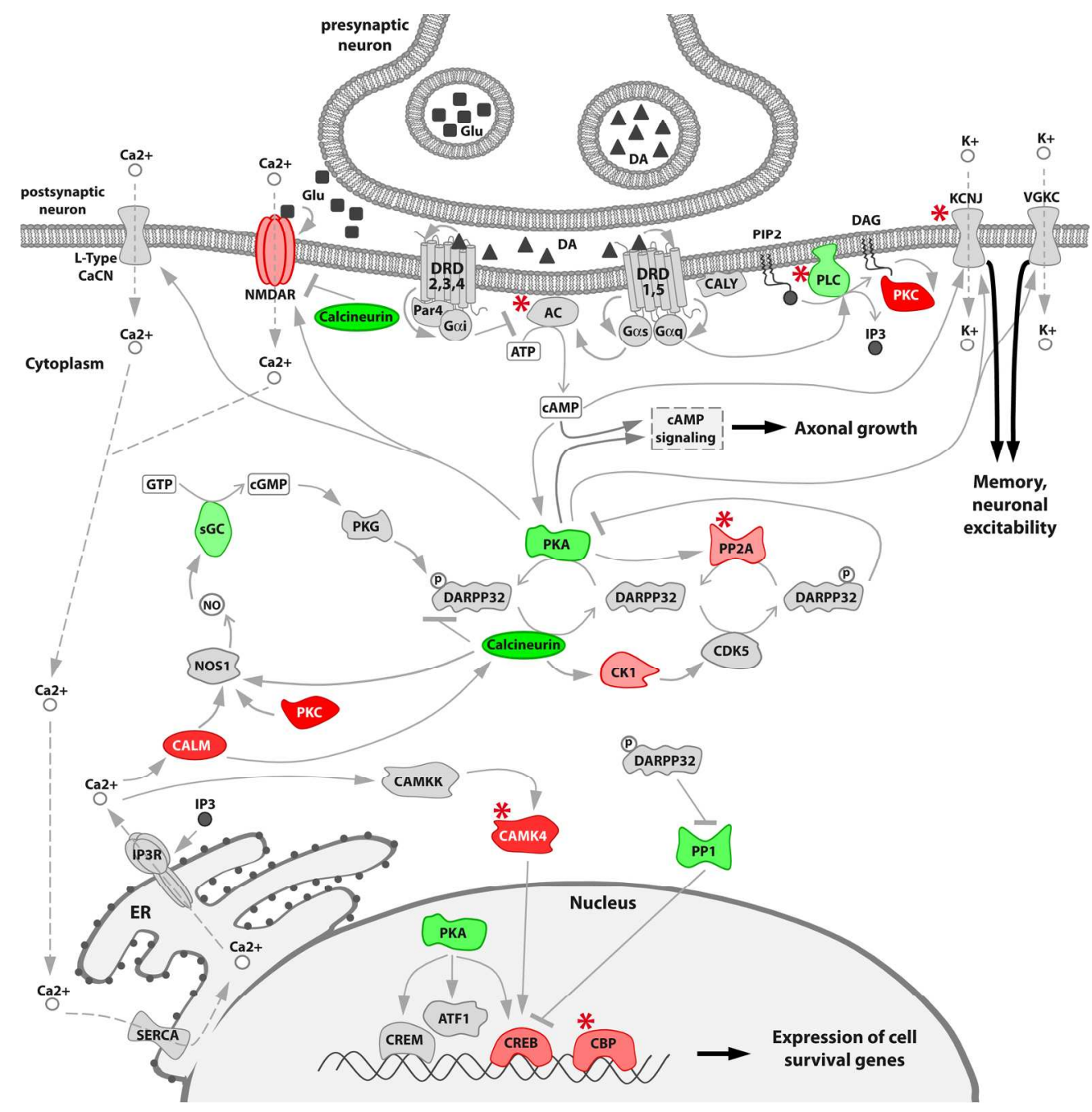

Figure 4. Dopamine-DARPP-32 feedback in CAMP signalling in frustration-like behaviour. The green and red nodes in this enriched canonical pathway indicate the down-regulated and up-regulated genes in the frustrated mice in ventral striatum and the red stars indicate up-regulated genes in the frustrated mice in frontal cortex.

$183 \times 186 \mathrm{~mm}(300 \times 300 \mathrm{DPI})$ 


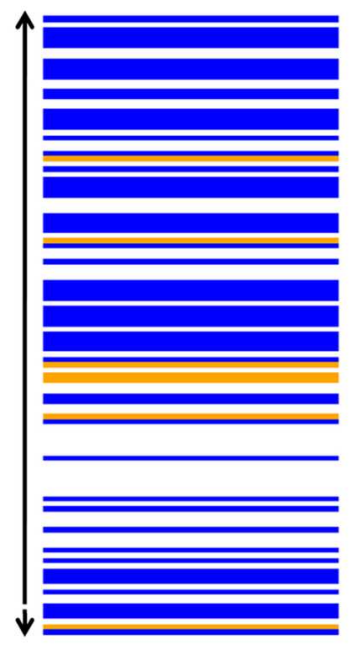

a

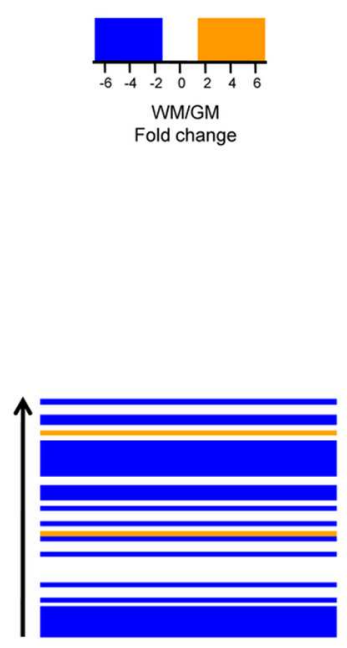

b

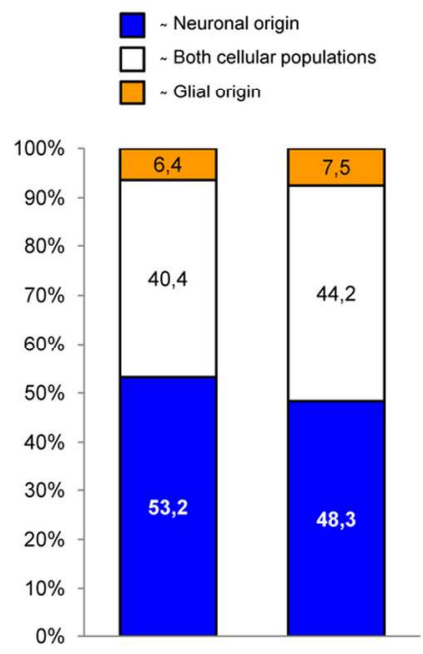

a

b

Figure 5. Glial/neuronal enrichment of altered gene expression in frontal cortex in the frustration model. (a) Transcripts differentially expressed $(n=116)$ in frontal cortex between frustrated and positive control mice and (b) transcripts differentially expressed $(n=47)$ in the frustrated mice but common in frontal cortex and ventral striatum. Left panel: Transcripts are organized vertically according to the extent of altered gene expression. Up and down arrows indicate up and down-regulation of gene expression, separated by a purple bar. Colour overlay indicates the cellular origin of the transcript: orange glial origin (white matter/grey matter: WM/GM>1.5), blue $\sim$ neuronal origin (WM/GM $<-1.5$ ) and white $\sim$ both cellular populations ($1.5>$ WM/GM < 1.5) (Sibille et al., 2008). Right panel: percentage of transcripts of each cell type origin. Note the apparent increased representation of neuronal expression in both cases.

$$
106 \times 62 \mathrm{~mm}(300 \times 300 \mathrm{DPI})
$$


A

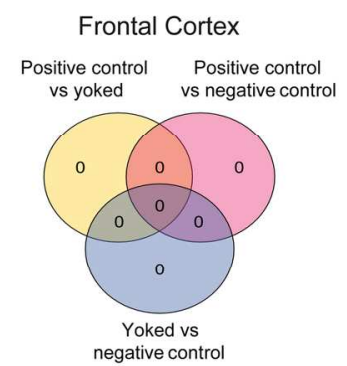

B

\begin{tabular}{|c|c|c|c|}
\cline { 2 - 4 } \multicolumn{1}{c|}{} & \multicolumn{3}{c|}{ Number of genes } \\
\cline { 2 - 4 } \multicolumn{1}{c|}{} & $\mathbf{1}$ & $\downarrow$ & Total \\
\hline Frontal cortex & - & - & - \\
\hline $\begin{array}{c}\text { Ventral } \\
\text { striatum }\end{array}$ & 138 & 12 & 210 \\
\hline Hippocampus & - & - & - \\
\hline
\end{tabular}

Ventral Striatum

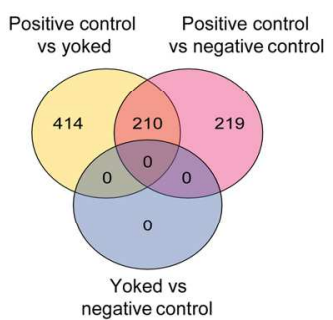

Hippocampus

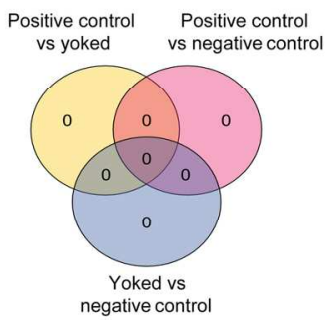

C

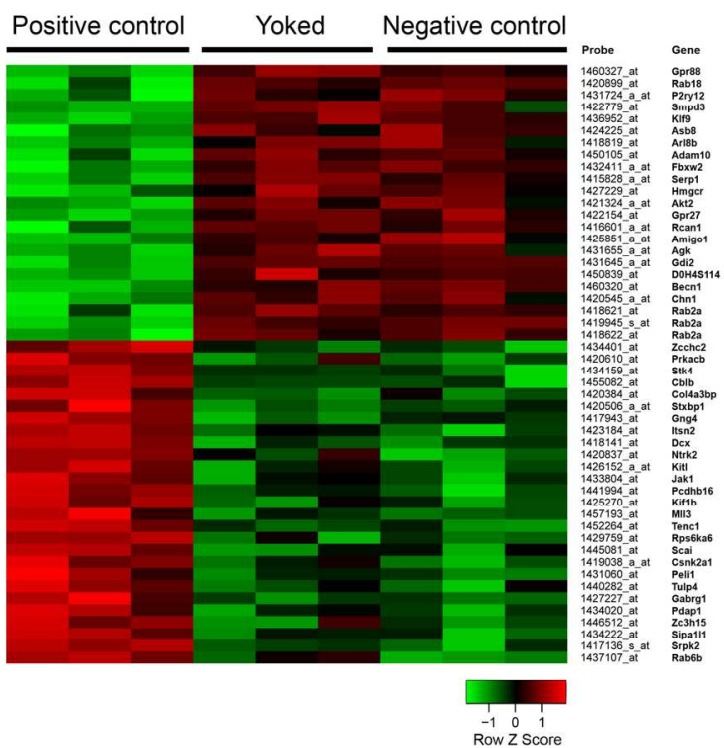

Figure 6. Gene expression changes caused by food self-administration reinforced learning. (a) Venn diagrams of genes differentially expressed in each comparison for the three brain areas. (b) Number of genes that are up-regulated or down-regulated only in mice that learned to self-administer the food (positive control), common in the comparison of positive control - yoked and positive control - negative control. (c) Cell communication enriched genes in food self-administration reinforced learning. Heatmap showing the level of expression in the microarray of the 48 genes identified in the GO:0007154 cell communication (adjP $=8.2 \mathrm{e}-3$ ). For each experimental group the three replicates are shown. $164 \times 151 \mathrm{~mm}(300 \times 300 \mathrm{DPI})$ 
A A Positive control
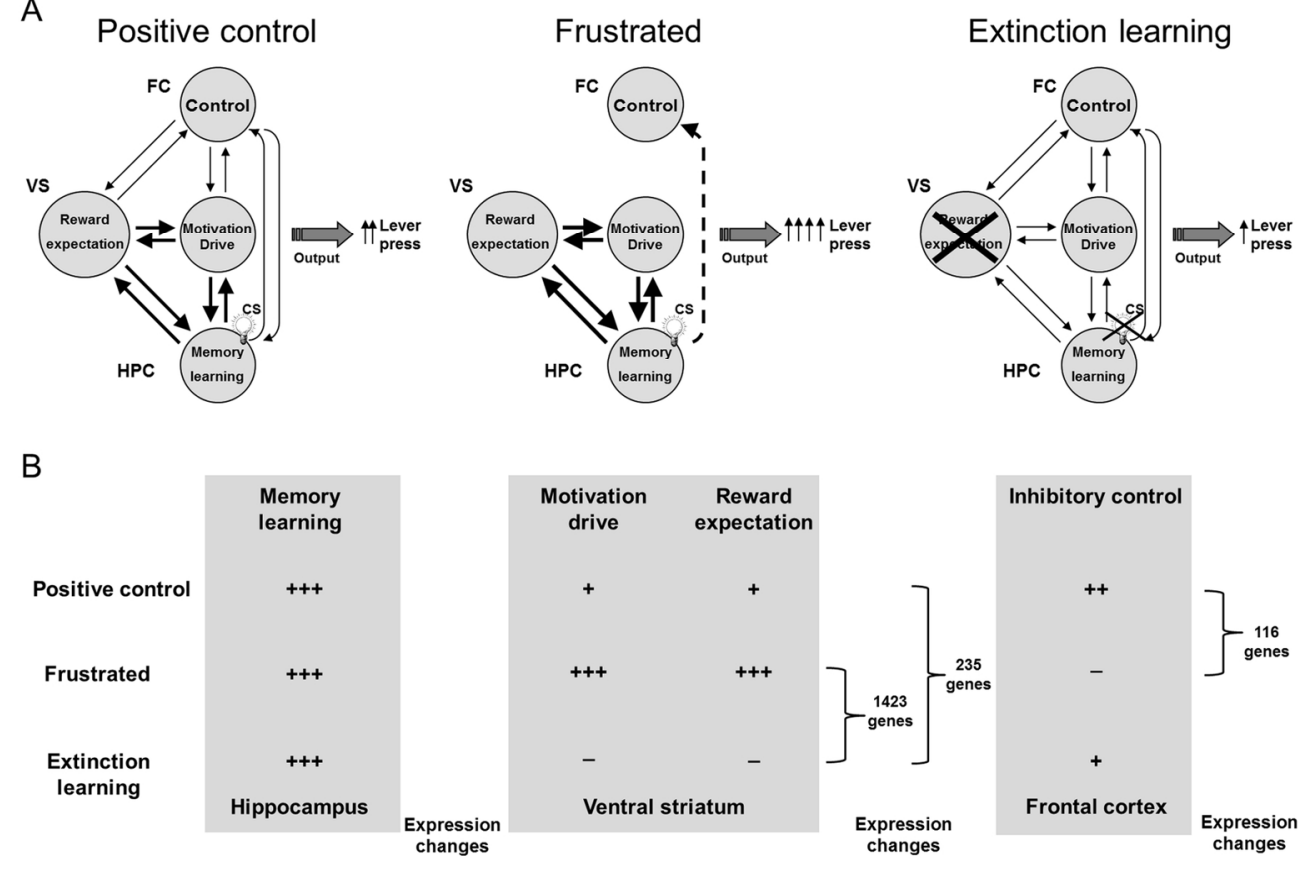

Figure 7. Theoretical model of frustration and extinction learning effects in mice behaviour and correlation with gene expression changes. (a) Model proposing a network of the main interacting circuits involved in addiction that may underlie frustration and extinction learning situations (adapted from (Volkow et al., 2003)). In positive control mice, the conditioned stimulus (CS) triggers an increased motivation for reward seeking (food) and also increases reward expectation in the ventral striatum (VS), leading to lever press. After the reward acquisition, there is an inhibitory control for the motivation exerted by the frontal cortex (FC). Frustrated mice do not receive a reward, and so no inhibition of the reward seeking is driven by FC, increasing motivation and reward expectation, and the number of lever-presses. Extinction learning mice behaviour is not driven by the CS, and the motivation for reward seeking therefore is not increased leading to a decreased expectation mediated by VS mechanisms. (b) Gene expression changes in each key brain region: hippocampus (HPC), VS and FC. No differences in HPC were detected since mice were exposed to the same training of active food self-administration. Those differences at VS and FC activation could lead to gene expression changes between each group, but they are not detectable in all comparisons. In VS, the most different group is extinction learning, without presence of cue-induced food-seeking, motivation and reward expectation, and so differences are only detected between this group and frustrated and positive

control mice. In FC, differences in gene expression are only detected between frustrated and positive control, which are expected to have opposite effects in this brain region. $152 \times 102 \mathrm{~mm}(300 \times 300 \mathrm{DPI})$ 